\title{
Electroluminescence from a Conjugated Polymer Grafted with CdSe/ZnS: High Brightness and Improved Efficiency
}

\author{
KUEI-BAI CHEN, ${ }^{1}$ MING-HWEY CHEN, ${ }^{1}$ SHENG-HSIUNG YANG, ${ }^{1}$ CHAO-HSIANG HSIEH, ${ }^{1}$ CHAIN-SHU HSU, ${ }^{1}$ \\ CHIA-CHUN CHEN, ${ }^{2}$ HSIAO-JU CHIEN ${ }^{3}$ \\ ${ }^{1}$ Department of Applied Chemistry, National Chiao Tung University, Hsinchu 30010, Taiwan, Republic of China \\ ${ }^{2}$ Department of Chemistry, National Taiwan Normal University, Taipei 116, Taiwan, Republic of China \\ ${ }^{3}$ Taiwan and Institute of Atomic Molecular Sciences, Academia Sinica, Taipei 106, Taiwan, Republic of China
}

Received 23 April 2006; accepted 26 May 2006

DOI: 10.1002 / pola.21608

Published online in Wiley InterScience (www.interscience.wiley.com).

\begin{abstract}
A new series of sulfide-substituted poly(1,4-phenylene vinylene) derivatives (S1PPV-S3PPV) with different composition ratios were successfully synthesized via the Gilch route. The CdSe/ZnS were grafted to the sulfur atoms by ligand exchange reaction. The grafted $\mathrm{CdSe} / \mathrm{ZnS}$ contents were determined from TGA analysis to be from 4.6 to $37.8 \%$. A new peak at $1151 \mathrm{~cm}^{-1}$ formed in FT-IR after ligand exchange, which is attributed to the force formation between sulfur and CdSe. The GPC results show that the molecular weights of final polymers became higher after ligand exchange. Thin films of obtained polymers emitted bright green and yellow light with the max emission peak located from 546 to $556 \mathrm{~nm}$. Double-layer LEDs with an ITO/PEDOT/polymer/Ca/Al configuration were fabricated to evaluate the potential use of these polymers. The turn-on voltages of the devices were about 4-5 V. As the CdSe/ZnS content increased in grafted polymers, the device performance was significantly enhanced as compared to pristine polymers. In the case of S3PPV, the double-layer device showed a maximum luminance of $6073 \mathrm{~cd} / \mathrm{m}^{2}$ with a current yield of $0.82 \mathrm{~cd} / \mathrm{A}$. The maximum luminance and current yield was enhanced to $13,390 \mathrm{~cd} / \mathrm{m}^{2}$ and $2.25 \mathrm{~cd} / \mathrm{A}$ by grafting CdSe/ZnS onto polymers. ( 2006 Wiley Periodicals, Inc. J Polym Sci Part A: Polym Chem 44: 5378-5390, 2006
\end{abstract}

Keywords: conjugated polymers; fluorescence; nanocomposites

\section{INTRODUCTION}

Semiconductor crystallites which are smaller than the bulk exciton diameter exhibit strong quantum size effects and are often refereed as quantum $\operatorname{dots}(\mathrm{QDs}){ }^{1}$ Optical properties such as fluorescence emission of QDs are critically dependent on the size of the nanocrystals. For examples, it has been shown that various sized CdSe nanocrystals

\footnotetext{
Correspondence to: C-S Hsu (E-mail: cshsu@mail.nctu. edu.tw)

Journal of Polymer Science: Part A: Polymer Chemistry, Vol. 44, 5378-5390 (2006) (ㅇ) 2006 Wiley Periodicals, Inc.
}

can fluoresce throughout the visible range of the electromagnetic spectrum with suitable control of the particle size. ${ }^{2}$ The adjustable and sharp emission characteristics of QDs make them interesting to be used in light emitting devices (LEDs). ${ }^{3}$ Colvin et al. reported the first polymer-QD LED of CdSe crystalline/PPV with ITO and $\mathrm{Mg} / \mathrm{Ag}$ electrodes. Since then, many unilayer, ${ }^{4,5}$ bilayer, $^{6,7}$ and trilayer ${ }^{8}$ polymer-QD LEDs have been reported. Unilayer polymer-QD LEDs have conductive and emissive species mixed together and are far below the theoretical performance limits. Bilayer polymer-QDs LEDs perform better than 
unilayer devices, but employ the QD layer as both emissive and electron transporting layer. The emissive layer is next to metal electrode, which causes quenching of emission. ${ }^{7}$ Chaudhary et al. reported a trilayer polymer-QDs LED fabricated by sandwiching a CdSe/ZnS core shall QD layer between films of polyvinylcarbazole and an oxadiazole derivative by a controlled spin-coating technique. The device showed much larger (20 times) quantum efficiency $(0.2 \%)$ and smaller threshold voltage $(5 \mathrm{~V})$ than those of a single layer device made from the PVK-QD-PBD blend. Recently Coe et al. demonstrated a trilayer hybrid organic-molecule-QD LED $^{19}$ in which a single monolayer of QDs, sandwiched between $\mathrm{Alq}_{3}$ (tris(8-hydroxyquinoline) aluminum) and TPD ( $N$, $N^{\prime}$-diphenyl- $N, N^{\prime}$-bis (3-methylphenyl)-(1,1-biphenyl)-(4,4'amine). The organic-molecule-QD LED showed a 25 fold improvement in luminescence $(1.6 \mathrm{~cd} / \mathrm{A}$ at $2000 \mathrm{~cd} /$ $\mathrm{m}^{2}$ ) over the best polymer QD-LED result. ${ }^{7}$ However, this value is still far below the efficiencies of the state-ofart organic LEDs. According to the study by Hikmet et al., ${ }^{7}$ the difficulty in hole injection into QDs due to the low laying HOMO level of CdSe QDs and each QD acting as an electron trap were considered to be the two reasons for the observed low efficiency.

Recently, several studies ${ }^{9-11}$ were focused on developing novel polymeric encapsulation strategies for CdSe nanoparticles. This approach combines these features with excellent processibility, film uniformity and reduces the tendency for CdSe nanoparticles toward aggregation. The CdSe nanoparticles are dispersed uniformly in a functionalized polymer matrix and lead to potential applications in LEDs and photovoltaic cells.

In this article, we report the syntheses, characterization, and electroluminescent properties of a series of sulfide-substituted PPV derivatives. The polymers in this article, S1PPV, S2PPV, and S3PPV, possess sulfide long chains to improve solubility in common organic solvents and link to $\mathrm{CdSe} / \mathrm{ZnS}$ via ligand exchange. In the device fabrication, double-layer devices using pristine polymer, polymer blended with $\mathrm{CdSe} / \mathrm{ZnS}$, and polymer grafted with $\mathrm{CdSe} / \mathrm{ZnS}$ as active layers were made and evaluated.

\section{EXPERIMENTAL}

\section{Characterization Methods}

The synthesized materials were characterized by the following techniques. FT-IR spectra were recorded on a Perkin-Elmer Spectrum One FT-IR spectrometer with $\mathrm{KBr}$ pellets. ${ }^{1} \mathrm{H}$ NMR spectra $(300 \mathrm{MHz})$ were recorded on a Varian VXR-300 spectrometer. Gel permeation chromatography (GPC) data assembled from Viscotek with an RI detector and three columns in series were used to measure the molecular weight distribution (MWD) relative to polystyrene standards at $40{ }^{\circ} \mathrm{C}$. Differential scanning calorimetry (DSC) was performed on a SEIKO DSC 6200 unit at a heating rate of $20^{\circ} \mathrm{C}$ $\mathrm{min}^{-1}$. TGA was undertaken on a Perkin-Elmer Pyris 1 TGA instrument with a heating rate of $10^{\circ} \mathrm{C} \mathrm{min}{ }^{-1}$. UV-vis spectra were obtained with an HP 8453 diode array spectrophotometer. Photoluminescence (PL) spectra were obtained using ARC SpectraPro-150 luminescence spectrometer.

A degassed $\mathrm{CHCl}_{3}$ solution was used to determine the PL quantum yields $\left(\varphi_{\mathrm{f}}\right)$. The concentration was adjusted to reduce the absorbance of the solution below 0.1 , and the excitation was performed at the corresponding $\lambda_{\text {ex }}$ max. A solution of quinine sulfate in $1 \mathrm{~N} \mathrm{H}_{2} \mathrm{SO}_{4}$, which has a $\varphi_{\mathrm{f}}$ of $0.546\left(\lambda_{\mathrm{ex}}=365 \mathrm{~nm}\right)$, was used as a standard. Cyclic voltammetric measurements of the material were made in acetonitrile with $0.1 \mathrm{M}$ tetrabutylammonium hexafluorophosphate $\left(\mathrm{TBAPF}_{6}\right)$ as the supporting electrolyte at a scan rate of $80 \mathrm{mV} / \mathrm{s}$. Platinum wires were used as both the counter and working electrodes, and silver/silver ions (Ag in $0.1 \mathrm{M} \mathrm{AgNO}_{3}$ solution, from Bioanalytical Systems, Switzerland) was used as the reference electrode. Ferrocene was used as an internal standard, and the potential values were obtained and converted to versus SCE (saturated calomel electrode). The corresponding highestoccupied molecular orbital (HOMO) and lowestunoccupied molecular orbital (LUMO) energy levels were estimated from the onset redox potentials. High-resolution transmission electron microscopy (TEM) was performed on a JEOL JEM-2010. TEM grids were purchased from Pentad and consisted of 3-4 nm amorphous carbon film supported on a 400-mesh copper grid.

\section{Materials}

All reagents and chemicals were purchased from commercial sources (Aldrich, Merck, Lancaster or TCI) and used without further purification. Tetrahydrofuran (THF) was dried by distillation from sodium/benzophenone. Scheme 1 lists the synthetic route for polymers S1PPV-S3PPV. The compound (4) was synthesized as described previously in the literature. ${ }^{12}$ 


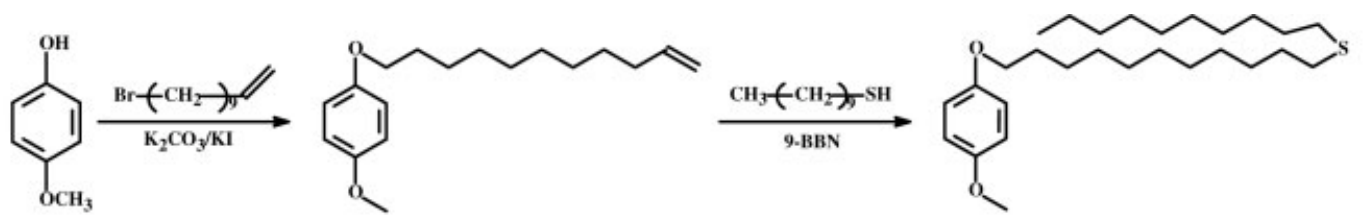

(1)

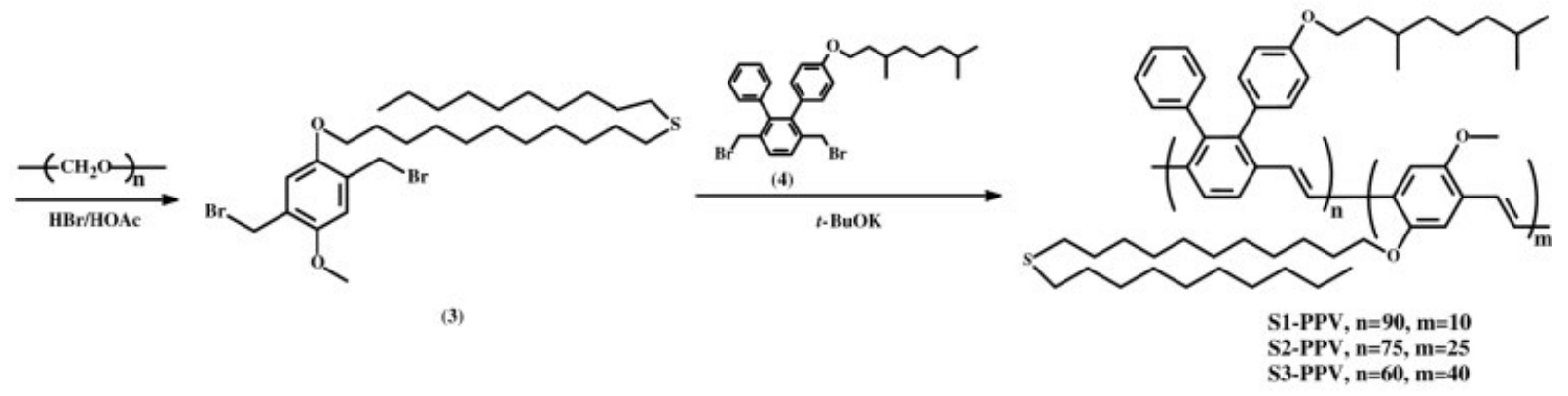

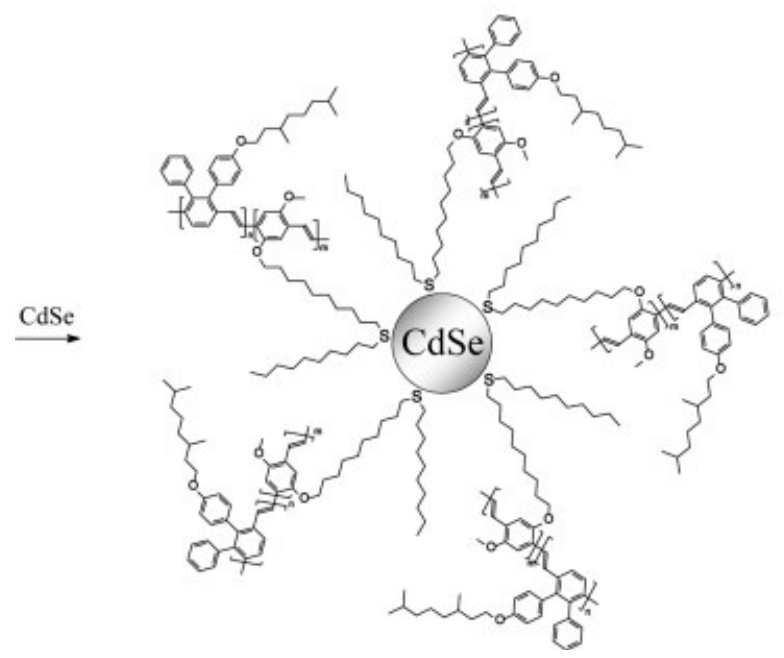

Scheme 1

\section{1-Methoxy-4-undec-10-enyloxybenzene (1)}

In a $100 \mathrm{~mL}$ three-neck flask, 4-methoxy phenol (2.9 g, $23.4 \mathrm{mmol})$, potassium carbonate (12.9 g, $93.5 \mathrm{mmol}$ ) and potassium iodide were dissolved in $80 \mathrm{~mL}$ of actonitrile. The mixture was refluxed at $90{ }^{\circ} \mathrm{C}$ overnight. The reaction mixture was cooled to room temperature, poured into a large amount of water, and extracted with ether. The combined organic layers were further washed with water several times, dried over anhydrous $\mathrm{MgSO}_{4}$, and filtered. The solvent was removed by evaporation under reduced pressure. The crude product was recrystallized from methanol to obtain a white solid $(4.3 \mathrm{~g}, 97 \%) \cdot \mathrm{mp} 42-43{ }^{\circ} \mathrm{C} .{ }^{1} \mathrm{H}$ NMR (300 MHz, $\left.\mathrm{CDCl}_{3}, \delta \mathrm{ppm}\right): 6.80$ (s, 4H, aromatic- $H), 5.78\left(\mathrm{~m}, 1 \mathrm{H}, \mathrm{CH}=\mathrm{CH}_{2}\right), 4.92(\mathrm{~m}, 2 \mathrm{H}$,
$\left.\mathrm{CH}=\mathrm{CH}_{2}\right), 3.95\left(\mathrm{t}, 2 \mathrm{H},-\mathrm{O}-\mathrm{CH}_{2}-\right), 3.82(\mathrm{~s}, 3 \mathrm{H}$, $\left.\mathrm{O}=\mathrm{CH}_{3}\right), 2.01\left(\mathrm{~m}, 2 \mathrm{H},-\mathrm{O}-\mathrm{CH}_{2}-\mathrm{CH}_{2}-\right), 1.72$ (m, 2H, $\left.-\mathrm{O}-\mathrm{C}_{2} \mathrm{H}_{4}-\mathrm{CH}_{2}-\right), 1.38$ (m, 12H, $-\mathrm{O}-\mathrm{C}_{3} \mathrm{H}_{6}-\mathrm{C}_{6} \mathrm{H}_{12}-\mathrm{CH}=\mathrm{CH}_{2}$ ).

\section{1-Methoxy-4-(11'-decylsulfanylundecanyloxy) benzene (2)}

In a $100 \mathrm{~mL}$ three-neck flask, 1 (4 g, $14.5 \mathrm{mmol})$ and 1-decanethiol ( $2.77 \mathrm{~g}, 15.9 \mathrm{mmol}$ ) were dissolved in THF. The reaction mixture was added 9-BBN (2.54 $\mathrm{mL}, 1.27 \mathrm{mmol}$ ) at $0{ }^{\circ} \mathrm{C}$. The solution was stirred overnight at room temperature. Subsequently, THF was evaporated; ether and water were then added. The organic layer was dried over $\mathrm{MgSO}_{4}$ and concentrated. The crude product was recrystallized from 
methanol to obtain a white solid (3.5 g, 54\%). mp 58$59{ }^{\circ} \mathrm{C} .{ }^{1} \mathrm{H}$ NMR $\left(300 \mathrm{MHz}, \mathrm{CDCl}_{3}, \delta \mathrm{ppm}\right): 6.80$ (s, $4 \mathrm{H}$, aromatic- $H$ ), $3.95\left(\mathrm{t}, 2 \mathrm{H},-\mathrm{O}-\mathrm{CH}_{2}-\right), 3.82(\mathrm{~s}$, $\left.3 \mathrm{H}, \mathrm{O}-\mathrm{CH}_{3}\right), 2.47\left(\mathrm{t}, 4 \mathrm{H},-\mathrm{CH}_{2}-\mathrm{S}-\mathrm{CH}_{2}-\right), 1.81$ (m, $6 \mathrm{H},-\mathrm{O}-\mathrm{CH}_{2}-\mathrm{CH}_{2}-,-\mathrm{CH}_{2}-\mathrm{CH}_{2}-\mathrm{S}-$ $\left.\mathrm{CH}_{2}-\mathrm{CH}_{2}-\right), \quad 1.55 \quad\left(\mathrm{~m}, \quad 30 \mathrm{H},-\mathrm{O}-\mathrm{C}_{2} \mathrm{H}_{4}-\right.$ $\left.\mathrm{C}_{7} \mathrm{H}_{14}-\mathrm{C}_{2} \mathrm{H}_{4}-\mathrm{S}-\mathrm{C}_{2} \mathrm{H}_{4}-\mathrm{C}_{7} \mathrm{H}_{14}-\mathrm{CH}_{3}\right), \quad 0.84$ (t, $3 \mathrm{H},-\mathrm{S}-\mathrm{C}_{9} \mathrm{H}_{18}-\mathrm{CH}_{3}$ ).

\section{1,4-Bis(bromomethyl)-2-(11' -decylsulfanylundeca- nyloxy)-5-methoxybenzene (3)}

In a $50 \mathrm{~mL}$ three-neck flask, $2(1.0 \mathrm{~g}, 2.2 \mathrm{mmol})$ and paraformaldehyde $(0.33 \mathrm{~g}, 11.0 \mathrm{mmol})$ were dissolved in acetic acid. The reaction mixture was added $33 \%$ hydrobromic acid in acetic acid (1.53 $\mathrm{mL}$ ) under a $\mathrm{N}_{2}$ atmosphere. The solution was stirred at $50{ }^{\circ} \mathrm{C}$ for $4 \mathrm{~h}$. The reaction mixture was cooled to room temperature, poured into excess water, and extracted with dichloromethane. The combined organic layers were further washed with water several times, dried over anhydrous $\mathrm{MgSO}_{4}$, and filtered. The solvent was removed by evaporation under reduced pressure. The crude product was recrystallized from methanol to obtain a white solid $(0.6 \mathrm{~g}, 43 \%) . \mathrm{mp} 89^{\circ} \mathrm{C}$. ${ }^{1} \mathrm{H}$ NMR (300 MHz, $\mathrm{CDCl}_{3}, \delta$ ppm): 6.83 (d, 2H, aromatic- $H$ ), 4.50 (d, $\left.4 \mathrm{H},-\mathrm{CH}_{2}-\mathrm{Br}\right), 3.95$ (t, $2 \mathrm{H}$, $\left.-\mathrm{O}-\mathrm{CH}_{2}-\right), 3.82\left(\mathrm{~s}, 3 \mathrm{H}, \mathrm{O}-\mathrm{CH}_{3}\right), 2.47(\mathrm{t}, 4 \mathrm{H}$, $\left.-\mathrm{CH}_{2}-\mathrm{S}-\mathrm{CH}_{2}-\right), \quad 1.81\left(\mathrm{~m}, 6 \mathrm{H},-\mathrm{O}-\mathrm{CH}_{2}\right.$ $\left.-\mathrm{CH}_{2}-,-\mathrm{CH}_{2}-\mathrm{CH}_{2}-\mathrm{S}-\mathrm{CH}_{2}-\mathrm{CH}_{2}-\right), \quad 1.55$ $\left(\mathrm{m}, 30 \mathrm{H},-\mathrm{O}-\mathrm{C}_{2} \mathrm{H}_{4}-\mathrm{C}_{7} \mathrm{H}_{14}-\mathrm{C}_{2} \mathrm{H}_{4}-\mathrm{S}-\mathrm{C}_{2} \mathrm{H}_{4}\right.$ $\left.-\mathrm{C}_{7} \mathrm{H}_{14}-\mathrm{CH}_{3}\right), 0.84\left(\mathrm{t}, 3 \mathrm{H},-\mathrm{S}-\mathrm{C}_{9} \mathrm{H}_{18}-\mathrm{CH}_{3}\right.$ ).

Synthesis of poly[2-(phenyl)-3-(4'-(3,7dimethyloctyloxy)phenyl)-1,4-phenylenevinylene-co-2-(11'-decyl sulfanylundecanyloxy)-5-methoxy-1,4-phenylene vinylene] (S1PPV-S3PPV)

An experimental procedure for the polymer S1PPV is given below. In a $100 \mathrm{~mL}$ three-neck flask, 3 (0.06 g, $0.1 \mathrm{mmol}), 4(0.5 \mathrm{~g}, 0.9 \mathrm{mmol})$ were dissolved in dry THF $(10 \mathrm{~mL})$. A solution of potassium tert-butoxide $(0.84 \mathrm{~g}, 7.5 \mathrm{mmol})$ in THF ( $28 \mathrm{~mL}$ ) was then added under a $\mathrm{N}_{2}$ atmosphere. The reaction mixture was stirred at room temperature for $24 \mathrm{~h}$. A solution of 2,6-di-tertbutylphenol $(0.5 \mathrm{~g}, 2.42 \mathrm{mmol})$ in THF was added and stirred for additional $7 \mathrm{~h}$. A large amount of methanol was added to the mixture to obtain the polymer $(0.15 \mathrm{~g}) .{ }^{1} \mathrm{H}$ NMR (300 $\left.\mathrm{MHz}, \mathrm{CDCl}_{3}, \delta \mathrm{ppm}\right): 7.11-6.3$ (br, $24 \mathrm{H}$, aromatic- $H$ and vinyl- $H$ ), 3.89 (br, $4 \mathrm{H},-\mathrm{O}-\mathrm{CH}_{2}-$ and $\left.\mathrm{O}-\mathrm{CH}_{3}\right), 2.46\left(\mathrm{br}, 1 \mathrm{H},-\mathrm{CH}_{2}-\mathrm{S}-\mathrm{CH}_{2}-\right.$ ), 1.53-0.86 (br, $40 \mathrm{H}$, alkyl-H).

\section{Synthesis of CdSe/ZnS Nanocrystals}

$0.012 \mathrm{~g}$ of $\mathrm{CdO}(0.1 \mathrm{mmol})$, and $0.114 \mathrm{~g}$ of stearic acid $((0.4 \mathrm{mmol})$ were loaded into a $25 \mathrm{~mL}$ three-neck flask and heated to $150{ }^{\circ} \mathrm{C}$ under $\mathrm{N}_{2}$ flow until $\mathrm{CdO}$ was completely dissolved. The color of solution changed from brown to colorless. The mixture was allowed to cool to room temperature. TOPO and hexadecylamine (HDA), $1.94 \mathrm{~g}$ of each, were added to the flask, and the mixture was heated to $300-350{ }^{\circ} \mathrm{C}$ under $\mathrm{N}_{2}$ flow to form an optically clear solution. When the temperature was stable, the Se solution containing $0.079 \mathrm{~g}$ ( $1 \mathrm{mmol})$ of Se dissolved in $2 \mathrm{~mL}$ of TBP was swiftly injected into the reaction flask. After the injection, the temperature was set at $180{ }^{\circ} \mathrm{C}$ for growth of the nanocrystals and kept about $1 \mathrm{~h}$. Subsequently, the $\mathrm{Zn} / \mathrm{S} / \mathrm{TBP}$ stock solution was added dropwise to the reaction solution at this temperature. After injecting, the reaction solution was cooled to room temperature. The reaction solution was mixed with chloroform then centrifuged to remove insoluble solid. The CdSe/ZnS nanocrystals were precipitated by adding methanol into the chloroform solution and isolated by centrifugation. The resulting precipitate was stored in $\mathrm{N}_{2}$ for future use.

\section{General Procedure for Ligand Exchange Reaction}

A solution of the ligand $(20 \mathrm{mg}$ in $1 \mathrm{~mL}$ of $\mathrm{CHCl}_{3}$ ) was added to the colloidal solution of CdSe nanocrystals $\left(10 \mathrm{mg}\right.$ in $1 \mathrm{~mL}$ of $\mathrm{CHCl}_{3}$ ). The obtained mixture was then stirred at constant temperature. The reaction was confirmed by FT-IR. After ligand exchange, the solution was precipitated into methanol to give the final polymer.

S1PPV-CdSe. Yellow solid. ${ }^{1} \mathrm{H}$ NMR $(300 \mathrm{MHz}$, $\mathrm{CDCl}_{3}, \delta \mathrm{ppm}$ ): 7.11-6.3 (br, $24 \mathrm{H}$, aromatic- $H$ and vinyl- $\mathrm{H}$ ), 3.89 (br, $4 \mathrm{H},-\mathrm{O}-\mathrm{CH}_{2}-$ and $\left.\mathrm{O}-\mathrm{CH}_{3}\right), 2.46\left(\mathrm{br}, \quad 1 \mathrm{H},-\mathrm{CH}_{2}-\mathrm{S}-\mathrm{CH}_{2}-\right.$ ), 1.53-0.86 (br, $40 \mathrm{H}$, alkyl-H).

S2PPV-CdSe. Orange solid. ${ }^{1} \mathrm{H}$ NMR $(300 \mathrm{MHz}$, $\left.\mathrm{CDCl}_{3}, \delta \mathrm{ppm}\right): 7.11-6.3$ (br, $10 \mathrm{H}$, aromatic- $H$ and vinyl- $\mathrm{H}$ ), 3.89 (br, $3 \mathrm{H},-\mathrm{O}-\mathrm{CH}_{2}-$ and $\left.\mathrm{O}-\mathrm{CH}_{3}\right), 2.46$ (br, $1 \mathrm{H},-\mathrm{CH}_{2}-\mathrm{S}-\mathrm{CH}_{2}-$ ), $1.53-0.86$ (br, $24 \mathrm{H}$, alkyl-H). 
S3PPV-CdSe. Orange solid. ${ }^{1} \mathrm{H}$ NMR $(300 \mathrm{MHz}$, $\mathrm{CDCl}_{3}, \delta \mathrm{ppm}$ ): 7.11-6.3 (br, $9 \mathrm{H}$, aromatic- $H$ and vinyl- $H$ ), $3.89\left(\mathrm{br}, 3 \mathrm{H},-\mathrm{O}-\mathrm{CH}_{2}-\right.$ and $\mathrm{O}-\mathrm{CH}_{3}$ ), $2.46\left(\mathrm{br}, 2 \mathrm{H},-\mathrm{CH}_{2}-\mathrm{S}-\mathrm{CH}_{2}-\right), 1.53-0.86$ (br, $26 \mathrm{H}$, alkyl-H).

\section{Device Fabrication}

Double-layer devices were fabricated as sandwich structures between calcium $(\mathrm{Ca})$ cathodes and indium-tin oxide (ITO) anodes. ITO-coated glass substrates were cleaned sequentially in ultrasonic baths of detergent, 2-propanol/deionized water (1:1 volume) mixture, toluene, deionized water and acetone. A $50 \mathrm{~nm}$-thick hole injection layer of poly(ethylenedioxythiophene) (PEDOT) doped with poly (styrenesulfonate) (PSS) was spin-coated on top of ITO from a $0.7 \mathrm{wt} \%$ dispersion in water and dried at $150{ }^{\circ} \mathrm{C}$ for $1 \mathrm{~h}$ in a vacuum. Thin films of synthesized polymers were spin-coated from toluene solutions onto the PEDOT layer and dried at $50{ }^{\circ} \mathrm{C}$ overnight in a vacuum. The thickness of the active layer was $\sim 50 \mathrm{~nm}$. Finally, $35 \mathrm{~nm} \mathrm{Ca}$ and $100 \mathrm{~nm}$ $\mathrm{Al}$ electrodes were made through a shadow mask onto the polymer films by thermal evaporation using an AUTO 306 vacuum coater (BOC Edwards, Wilmington, MA). Evaporations were carried out typically at base pressures lower than $8 \times 10^{-7}$ Torr. The active area of each EL device was $4 \mathrm{~mm}^{2}$.

\section{RESULTS AND DISCUSSION}

\section{Synthesis and Characterization}

The synthetic routes of S1PPV-S3PPV are shown in Scheme 1. The monomer 1,4-bis-(bromomethyl)2-(11'-decylsulfanyl undecanyloxy)-5-methoxybenzene (3) with sulfide group was synthesized in three steps. 1-methoxy-4-undec-10-enyloxy benzene (1) was synthesized from the reaction of 4-methoxyphenol and 1-bromoundecene through the Williamson ether synthesis. The compound (1) and 1-decanethiol was treated with 9-BBN in THF to give 1methoxy-4-(11'-decylsulfanylundecanyloxy)benzene $(\mathbf{2}){ }^{13}(\mathbf{3})$ was synthesized from (2) and paraformaldehyde in $\mathrm{HBr} / \mathrm{CH}_{3} \mathrm{COOH}$ solution. The Gilch route was applied to carry out the polymerization. This reaction occurs through base-promoted 1,6-elimination of 1,4-bis(halomethyl)benzenes. The polymerization condition is mild and the molecular weights of obtained polymers are pretty large. The copolymerization of (3) and 1,4-bis(bromomethyl)-2-[4'-

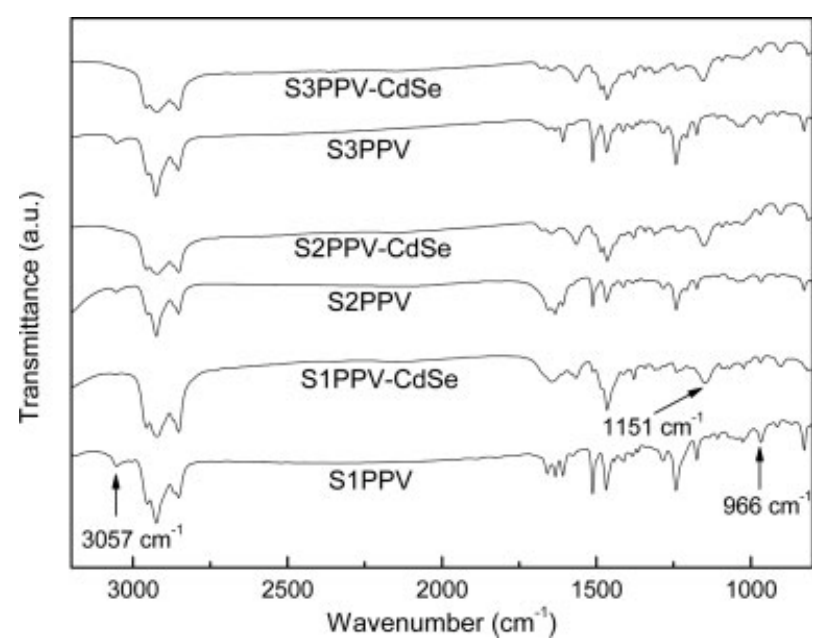

Figure 1. FT-IR spectra of S1PPV-S3PPV and S1PPV-CdSe-S3PPV-CdSe.

(3,7-dimethyloctyloxy)phenyl]-3-phenyl benzene (4) were carried out with an excess of potassium tertbutoxide in THF at room temperature for $24 \mathrm{~h}$ under a nitrogen atmosphere. The light yellow (S1PPV) and orange (S2PPV, S3PPV) polymers can be obtained by pouring the reaction mixture into methanol. The obtained polymers S1PPVS3PPV were then reacted with $\mathrm{CdSe} / \mathrm{ZnS}$ via ligand exchange reaction ${ }^{14}$ to give the final polymer S1PPV-CdSe-S3PPV-CdSe. The FT-IR technique was then applied to verify the chemical structure of the organic/inorganic hybrid material. Figure 1 shows the FT-IR spectra of S1PPV-S3PPV and S1PPV-CdSe-S3PPV-CdSe. The PPV derivatives shows the phenyl and alkenyl $\mathrm{C}-\mathrm{H}$ stretching bands at $3057 \mathrm{~cm}^{-1}$ and the trans-vinylene out-ofplane $\mathrm{C}-\mathrm{H}$ bending band at $966 \mathrm{~cm}^{-1} \cdot 15$ The signal of the cis-vinylene double bond at $858 \mathrm{~cm}^{-1}$ was not detectable because of the bulkyl diphenyl group on the main chain. It is concluded that the steric effect decreases the cis-linkage during polymerization. A new peak at $1151 \mathrm{~cm}^{-1}$ formed after ligand exchange. This is attributed to the force formation between sulfur and CdSe. The final composite material is soluble in common solvents such as chloroform $\left(\mathrm{CHCl}_{3}\right)$, chlorobenzene, and tetrahydrofuran.

Figure 2 shows the transmission electron micrographs of S1PPV-CdSe-S3PPV-CdSe. The average diameter of CdSe nanocrystals is about 4-5 nm. This is the exact size of CdSe that we chose to carry out the ligand exchange reaction. It is seen that CdSe dispersed homogeneously; the aggregation of nanocrystals was not observed. The benefit is that the incorporation of CdSe into poly- 
(a)

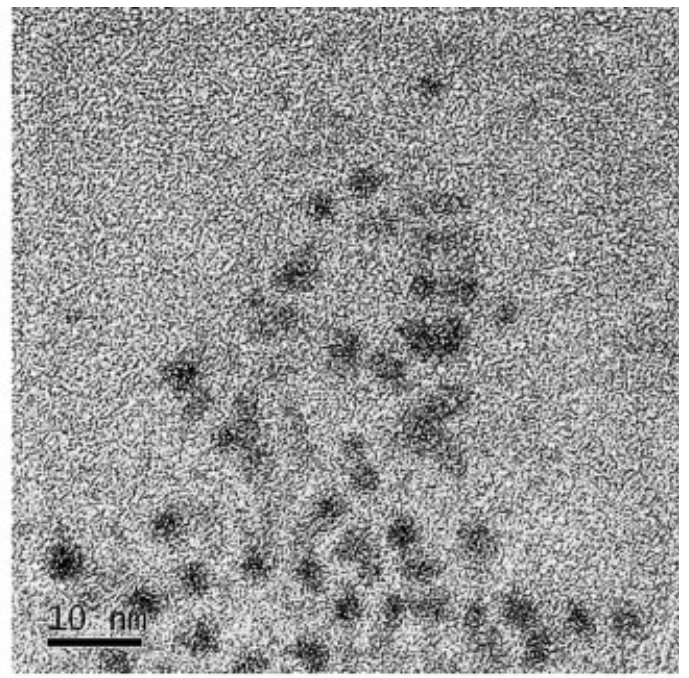

(b)

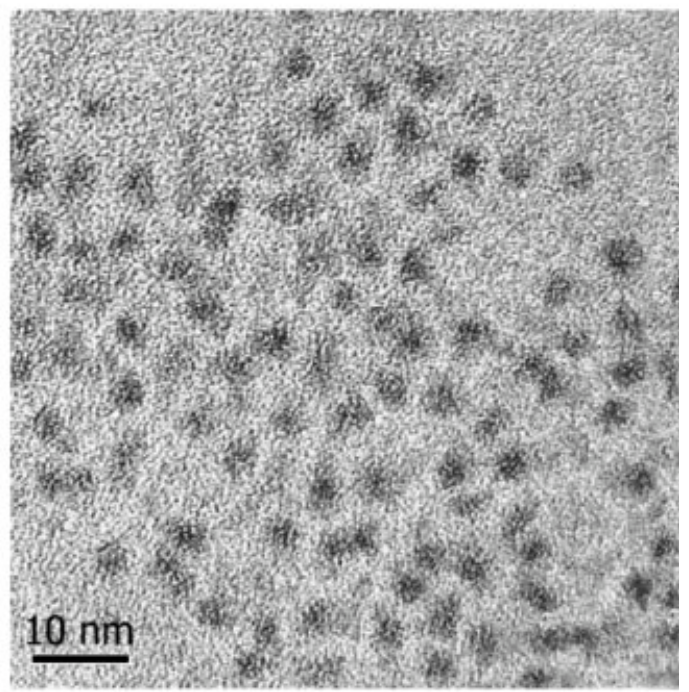

(c)

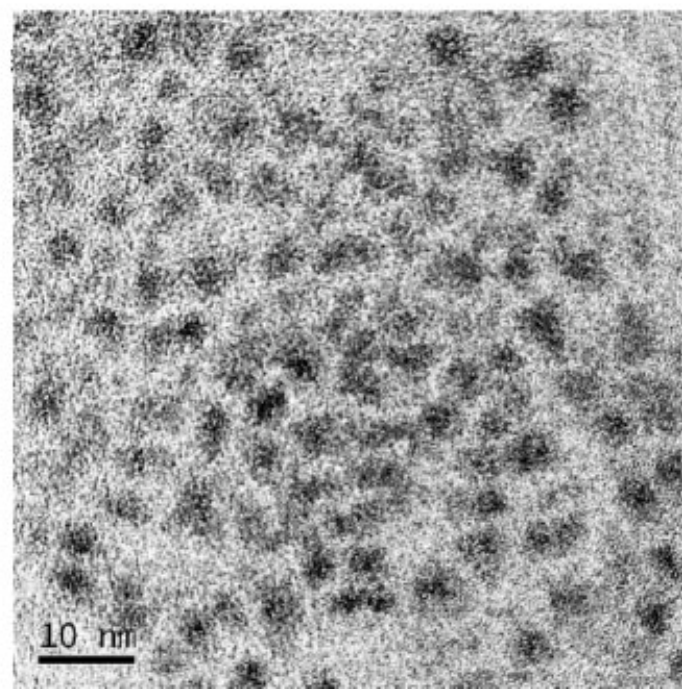

Figure 2. TEM micrographs of (a) S1PPV-CdSe, (b) S2PPV-CdSe, and (c) S3PPV-CdSe.

Journal of Polymer Science: Part A: Polymer Chemistry DOI 10.1002/pola mers by chemical bonding is better than conventional blending method, that inhomogeneous dispersion of nanoparticles is usually found. Figure 3 shows the GPC profile of S2PPV and S2PPVCdSe. It is seen that the elution time decreases after ligand exchange. The number-average molecular weight $\left(M_{\mathrm{n}}\right)$ of S2PPV was 496600 with polydispersity index $\left(\mathrm{PDI}=M_{\mathrm{w}} / M_{\mathrm{n}}\right)$ of 1.9 . After linking the polymer to CdSe, the $M_{\mathrm{n}}$ of S2PPVCdSe was 522200 (PDI 2.56). This indicates that the molecular weight of the final polymer becomes higher after ligand exchange, referring successful incorporation of CdSe/ZnS onto polymers. Similar condition of increasing molecular weight was also observed for S1PPV-CdSe and S3PPV-CdSe. The $M_{\mathrm{n}}$ of S1PPV and S3PPV was 204300 (PDI 1.04) and 200800 (PDI 5.22), respectively. After the ligand exchange reaction, the $M_{\mathrm{n}}$ of S1PPVCdSe and and S3PPV-CdSe became 216000 (PDI 1.07) and 255900 (PDI 5.57), respectively. The results above reveal that $\mathrm{CdSe} / \mathrm{ZnS}$ were grafted onto polymer S1PPV and S3PPV. The thermal properties of these PPV derivatives are summarized in Table 1. The glass transition temperatures $\left(T_{\mathrm{g}}\right)$ of these derivatives are in the range from 185 to $224{ }^{\circ} \mathrm{C}$, while no melting transition is observed; this indicates that the polymers have amorphous structures. The high $T_{\mathrm{g}}$ values of present polymers promote to prevent the deformation of chain morphology and degradation of the emissive layer under applied electric fields. The CdSe-grafting polymers show lower $T_{\mathrm{g}}$ as compared with their parent polymers. The reason comes from the nature of $\mathrm{CdSe} / \mathrm{ZnS}$ which are capped with organic molecules TOPO. The CdSe/ ZnS QDs are softer than synthesized polymers

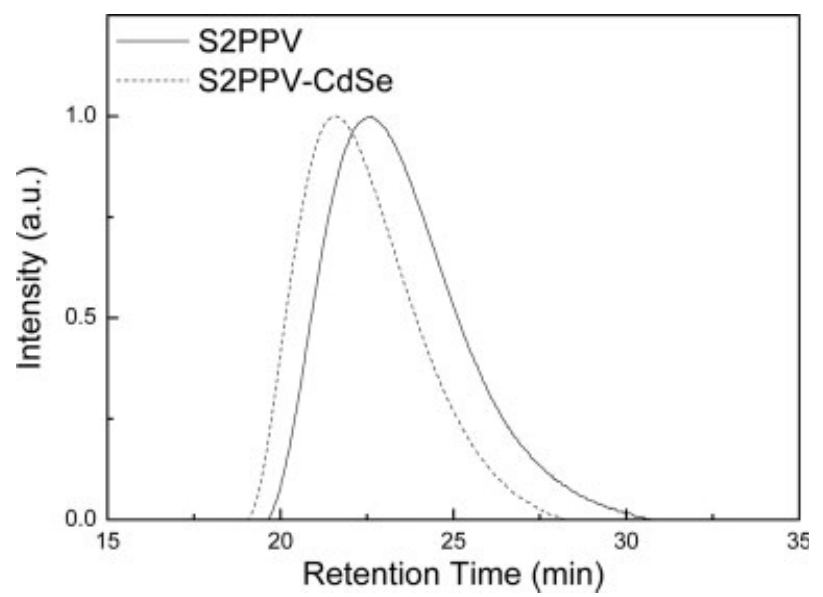

Figure 3. GPC profiles of S2PPV and S2PPVCdSe. 
Table 1. Composition and Thermal Properties of Polymers

\begin{tabular}{lccccc}
\hline \multicolumn{1}{c}{ Material } & $X$ mol $(\%)$ & $Y$ mol $(\%)$ & QDs content $(\%)$ & $T_{\mathrm{g}}\left({ }^{\circ} \mathrm{C}\right)$ & $T_{\mathrm{d}}\left({ }^{\circ} \mathrm{C}\right)$ \\
\hline S1PPV & 90 & 10 & & 187 & 438 \\
S1PPV-CdSe & 90 & 10 & 4.6 & 186 & 443 \\
S2PPV & 75 & 25 & & 224 & 412 \\
S2PPV-CdSe & 75 & 25 & 14.6 & 192 & 417 \\
S3PPV & 60 & 40 & & 194 & 413 \\
S3PPV-CdSe & 60 & 40 & 37.8 & 185 & 415 \\
\hline
\end{tabular}

and show a lower $T_{g}$. Since CdSe/ZnS were incorporated onto polymer chains, they may increase the free volume of the main chain and thus decrease the $T_{\mathrm{g}}$ of final materials. The decomposed temperatures $\left(T_{\mathrm{d}}\right)$ of PPV derivatives obtained from TGA are in the range from 412 to $438{ }^{\circ} \mathrm{C}$. This reveals that all materials possess excellent thermal stability over $400{ }^{\circ} \mathrm{C}$. It is noted that the $T_{\mathrm{d}}$ decreases as the content of 2-(11'-decyl sulfanylundecanyloxy)-5-methoxy-1,4-phenylene vinylene moiety increases. This is reasonable since long alkyl chain has lower thermal stability and decrease the $T_{\mathrm{d}}$ value. The TGA measurement was made up to $750{ }^{\circ} \mathrm{C}$, and the residue was considered to be char (from polymers) and CdSe/ZnS. By subtracting the char content, the CdSe/ZnS content in the polymer was determined to be 4.6 , 24.6, and 37.8 wt \% for S1PPV-CdSe, S2PPVCdSe, and S3PPV-CdSe, respectively. The CdSe/ $\mathrm{ZnS}$ content increases as the sulfide groups increase. It is obvious that more sulfide groups can act as ligands to bind $\mathrm{CdSe} / \mathrm{ZnS}$.

\section{Optical Properties}

The UV-vis absorption and PL emission maxima of S1PPV-S3PPV and S1PPV-CdSeS3PPV-CdSe are summarized in Table 2. The maximum absorption bands of pristine polymers are located at 444-455 nm in $\mathrm{CHCl}_{3}, 446-457$ $\mathrm{nm}$ in chlorobenzene, and $439-461 \mathrm{~nm}$ in film state. This is attributed to the $\pi-\pi^{*}$ transition of the PPV backbone. The similar positions of the absorption band in both solution and film states imply effective hindrance by the bulky diphenyl groups and long alkoxy chains. The band gaps of S1PPV, S2PPV, and S3PPV are different according to the compositions of two repeating units. It is worth to note that the maximum emission bands of S1PPV in $\mathrm{CHCl}_{3}$, chlorobenzene and film state were all located at $546 \mathrm{~nm}$. It is generally thought that the red-shift from solution to film state comes from the effect of interchain $\pi$-stacking, i.e., the formation of aggregation in solid film state. When the photophysical properties in two states approach to each other, the extent of aggregation reduces. ${ }^{16}$ The similar PL spectra of S1PPV obtained in both solution and film states indicate that no or less extent of aggregation occurred. The $\varphi_{\mathrm{f}}$ values are in the range of $72-92 \%$ in chlorobenzene and $54-80 \%$ in film state, ${ }^{17}$ which are quite high values compared with traditional conjugated polymers. Turing to the CdSe-grafting materials, the maximum absorption and emission bands were similar as compared to their parent poly-

Table 2. Optical Properties of Polymers

\begin{tabular}{|c|c|c|c|c|c|c|c|c|}
\hline \multirow[b]{2}{*}{ Materials } & \multicolumn{3}{|c|}{$\mathrm{UV}\left[\lambda_{\max }(\mathrm{nm})\right]$} & \multicolumn{5}{|c|}{$\mathrm{PL}\left[\lambda_{\max }(\mathrm{nm})\right]$} \\
\hline & $\mathrm{CHCl}_{3}$ & $\mathrm{CB}$ & Film & $\mathrm{CHCl}_{3}$ & $\mathrm{CB}$ & $\mathrm{QE}^{\mathrm{a}}$ & Film & $\mathrm{QE}^{\mathrm{b}}$ \\
\hline S1PPV & 444 & 446 & 439 & 546 & 546 & 92 & 546 & 80 \\
\hline S1PPV-CdSe & 446 & 446 & 439 & 544 & 546 & 96 & 548 & 83 \\
\hline S2PPV & 452 & 457 & 449 & 554 & 559 & 79 & 551 & 71 \\
\hline S2PPV-CdSe & 455 & 455 & 458 & 554 & 561 & 85 & 553 & 75 \\
\hline S3PPV & 455 & 457 & 461 & 554 & 560 & 74 & 556 & 54 \\
\hline S3PPV-CdSe & 455 & 458 & 463 & 552 & 558 & 76 & 554 & 62 \\
\hline
\end{tabular}

${ }^{a}$ Measured in solution state.

${ }^{\mathrm{b}}$ Measure in film state. 
Table 3. Electrochemical Properties of Polymers

\begin{tabular}{|c|c|c|c|c|c|}
\hline & \multirow[b]{2}{*}{ UV edge (nm) } & \multirow[b]{2}{*}{$E_{\text {ox }, \text { onset }}(\mathrm{V})$} & \multicolumn{3}{|c|}{ Energy level (eV) } \\
\hline & & & HOMO & LUMO & $\mathrm{Eg}$ \\
\hline S1PPV & 509 & 0.79 & 5.39 & 2.96 & 2.43 \\
\hline S1PPV-CdSe & 510 & 0.76 & 5.36 & 2.93 & 2.43 \\
\hline S2PPV & 535 & 0.69 & 5.29 & 2.98 & 2.31 \\
\hline S2PPV-CdSe & 537 & 0.65 & 5.25 & 2.94 & 2.31 \\
\hline S3PPV & 540 & 0.68 & 5.28 & 2.98 & 2.30 \\
\hline S3PPV-CdSe & 539 & 0.65 & 5.25 & 2.95 & 2.30 \\
\hline
\end{tabular}

mers. No energy transfer between the polymer and CdSe was observed in the case. This suggests that incorporating CdSe onto polymer chains does not affect the conjugated length of the main chain. This may be because the weight ratio of CdSe is small compared to the polymer. On the other hand, CdSe were not directly attached to the main chain because of long alkoxy group between sulfur and benzene ring. The $\varphi_{\mathrm{f}}$ values are in the range of $76-96 \%$ in chlorobenzene and $62-83 \%$ in film state, which are higher than those of pristine polymers.

\section{Electrochemical Properties}

Cyclic voltammetric (CV) analysis was performed to measure the electrochemical behavior, HOMO, and LUMO energy levels of the polymers. The electrochemical data of polymers S1PPV-S3PPV and S1PPV-CdSe-S3PPV-CdSe are summarized in Table 3. The polymers S1PPV_ S3PPV exhibited irreversible $p$-doping process in the anodic scan. The onsets of oxidation potentials were in the range of $0.65-0.79 \mathrm{~V}$, referring their HOMO energy levels as 5.28-5.39 eV. The band gaps of the polymers were estimated from their absorption edge in film state, which are in the range of $2.3-2.43 \mathrm{eV}$. Combining the electrochemical data and UV-vis characteristics gives an estimate of the LUMO energy levels. We notice that the HOMO binding energy of the copolymers increased as the content of sulfide group increased, giving a narrower band gap. Turning to CdSe-grafting polymers, it is seen that band gaps were not significantly affected by incorporating CdSe/ZnS onto the polymer, while HOMO and LUMO were shifted to higher levels. It should be noted that the energy levels of CdSe/ZnS are normally estimated by theoretical calculation and can not be measured by CV analysis. ${ }^{18}$ The energy level diagram of S1PPV-CdSe-S3PPVCdSe and CdSe is depicted in Figure 4.

\section{Electroluminescence Properties of LED Devices}

Double-layer light-emitting devices with the configuration of ITO/PEDOT/polymer/Ca/Al were fabricated to evaluate the potential of synthesized materials. In addition to pristine and CdSe-grafting polymers, polymers S1PPV-S3PPV were also blended with equal amount of CdSe (Table 1) and used as active layers. The three blended materials were named S1PPV/CdSe, S2PPV/CdSe, and S3PPV/CdSe for comparison. The device using S1PPV as active layer emitted green light at 544 $\mathrm{nm}$ with the CIE 1931 coordinate at $(0.42,0.56)$. The devices using S1PPV-CdSe and S1PPV/ CdSe also showed similar EL emission spectra. The current density and luminescence-voltage characteristics of the devices are shown in Figure 4. Taking S1PPV as example, the device showed a turn-on voltage of $4 \mathrm{~V}$ with a luminance of $146 \mathrm{~cd} / \mathrm{m}^{2}$. It showed a maximum luminance of $8285 \mathrm{~cd} / \mathrm{m}^{2}$ at $9 \mathrm{~V}$ with a luminous yield of $0.79 \mathrm{~cd} / \mathrm{A}$. By using S1PPV/CdSe as active layer, the device showed a turn-on voltage of $4 \mathrm{~V}$ with a luminance of $107 \mathrm{~cd} / \mathrm{m}^{2}$. The maximum luminance was $8158 \mathrm{~cd} / \mathrm{m}^{2}$ at $9 \mathrm{~V}$ with a luminous yield of $0.86 \mathrm{~cd} / \mathrm{A}$. It is seen that S1PPV blended with CdSe would slightly affect the device performance. By using S1PPV-CdSe as light-emitting layer, the turn-on voltage became $4 \mathrm{~V}$; the maximum luminance was highly enhanced to $15,960 \mathrm{~cd} / \mathrm{m}^{2}$ at $9 \mathrm{~V}$ with a luminous yield of $1.47 \mathrm{~cd} / \mathrm{A}$. In the case of S2PPV, the turn-on voltage was $4 \mathrm{~V}$ with a luminance of $134 \mathrm{~cd} / \mathrm{m}^{2}$; it showed a maximum luminance of $3225 \mathrm{~cd} / \mathrm{m}^{2}$ at $8 \mathrm{~V}$ with a luminous yield of $0.95 \mathrm{~cd} / \mathrm{A}$. By using S2PPV/CdSe as active layer, the turn-on voltage was $4 \mathrm{~V}$ with a luminance of $191 \mathrm{~cd} / \mathrm{m}^{2}$. The device showed a maximum luminance of $3910 \mathrm{~cd} / \mathrm{m}^{2}$ at $9 \mathrm{~V}$ with a 


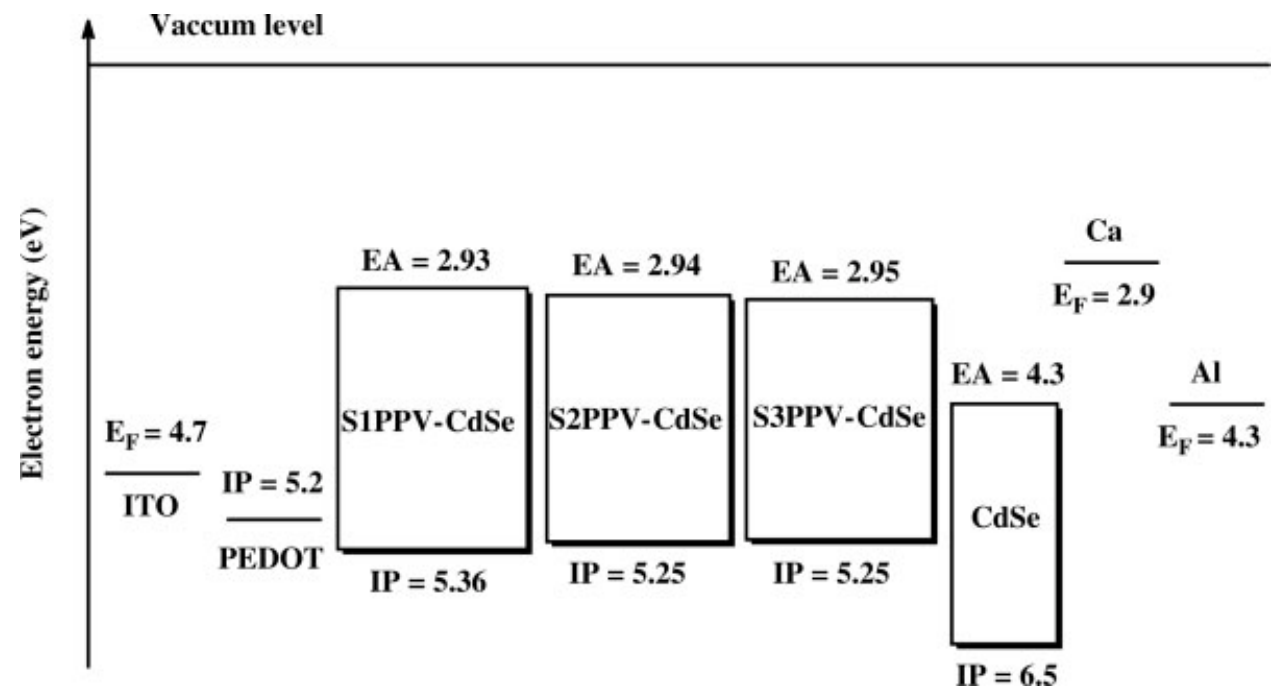

Figure 4. Energy level diagram of S1PPV-CdSe-S3PPV-CdSe and CdSe.

luminous yield of $1.25 \mathrm{~cd} / \mathrm{A}$. Here the $\mathrm{CdSe} / \mathrm{ZnS}$ content was somewhat optimized to improve the device performance. By using S2PPV-CdSe as light-emitting layer, the turn-on voltage became $5 \mathrm{~V}$; it showed a maximum luminance of 14,470 $\mathrm{cd} / \mathrm{m}^{2}$ at $12 \mathrm{~V}$ with a luminous yield of $1.85 \mathrm{~cd} / \mathrm{A}$. The devices using S2PPV or S2PPV-CdSe as active layers both emitted yellow light at $552 \mathrm{~nm}$ with the CIE 1931 coordinate at $(0.45,0.54)$. Turning to S3PPV, the turn-on voltage was $4 \mathrm{~V}$ with a luminance of $86 \mathrm{~cd} / \mathrm{m}^{2}$; it showed a maximum luminance of $6073 \mathrm{~cd} / \mathrm{m}^{2}$ at $9 \mathrm{~V}$ with a luminous yield of $0.82 \mathrm{~cd} / \mathrm{A}$. By using S3PPV/CdSe as active layer, the turn-on voltage was $4 \mathrm{~V}$ with a luminance of $16 \mathrm{~cd} / \mathrm{m}^{2}$; it showed a maximum luminance of $8195 \mathrm{~cd} / \mathrm{m}^{2}$ at $11 \mathrm{~V}$ with a luminous yield of $1.09 \mathrm{~cd} / \mathrm{A}$. By using S3PPV-CdSe as lightemitting layer, the turn-on voltage was $4 \mathrm{~V}$ with a luminance of $17 \mathrm{~cd} / \mathrm{m}^{2}$; it showed a maximum luminance of $13,990 \mathrm{~cd} / \mathrm{m}^{2}$ at $11 \mathrm{~V}$ with a luminous yield of $2.25 \mathrm{~cd} / \mathrm{A}$. The devices using S3PPV or S3PPV-CdSe as active layers both emitted yellow light at $554 \mathrm{~nm}$ with the CIE 1931 coordinate at $(0.46,0.53)$. It should be noted that no emission from CdSe is observed in our case. We consider that the emission of QDs was relatively low as compared to highly luminescent polymers. Our research showed a quite different result on the device enhancement by incorporating QDs into lightemitting polymers, instead of its self-luminance. To our best knowledge, the best device performance of QD-based LEDs was reported with maximum brightness of about $2000 \mathrm{~cd} / \mathrm{m}^{2}$, which is not competitive with conventional organic materials (Table 4). ${ }^{19}$

The improved electroluminescent properties using CdSe-grafting polymers as active layers were interpreted in two ways: the charge trapping effect,

Table 4. Device Performance of polymers in ITO/PEDOT/polymer/Ca/Al Devices

\begin{tabular}{lccccc}
\hline \multicolumn{1}{c}{ Material } & $\begin{array}{c}\text { EL }\left[\lambda_{\max }(\mathrm{nm})\right] \\
\text { at } V_{\text {turn on }}\end{array}$ & $\begin{array}{c}V_{\text {turn on }} \\
(\mathrm{V})\end{array}$ & $\begin{array}{c}\text { Luminance } \\
\left(\mathrm{Max} ; \mathrm{cd} / \mathrm{m}^{2}\right)\end{array}$ & $\begin{array}{c}\text { Yield } \\
(\mathrm{Max}) \\
(\mathrm{cd} / \mathrm{A})\end{array}$ & $\begin{array}{c}\text { CIE1931 } \\
(x, y)\end{array}$ \\
\hline S1PPV & 544 & 4 & 8285 & 0.79 & $(0.42,0.56)$ \\
S1PPV/CdSe & 544 & 4 & 8158 & 0.86 & $(0.41,0.56)$ \\
S1PPV-CdSe & 544 & 4 & 15960 & 1.47 & $(0.41,0.56)$ \\
S2PPV & 552 & 4 & 3225 & 0.95 & $(0.45,0.54)$ \\
S2PPV/CdSe & 552 & 4 & 3910 & 1.25 & $(0.47,0.52)$ \\
S2PPV-CdSe & 552 & 5 & 14470 & 1.85 & $(0.47,0.52)$ \\
S3PPV & 556 & 4 & 6073 & 0.82 & $(0.46,0.53)$ \\
S3PPV/CdSe & 556 & 4 & 8195 & 1.09 & $(0.46,0.53)$ \\
S3PPV-CdSe & 556 & 4 & 13390 & 2.25 & $(0.46,0.53)$ \\
\hline
\end{tabular}



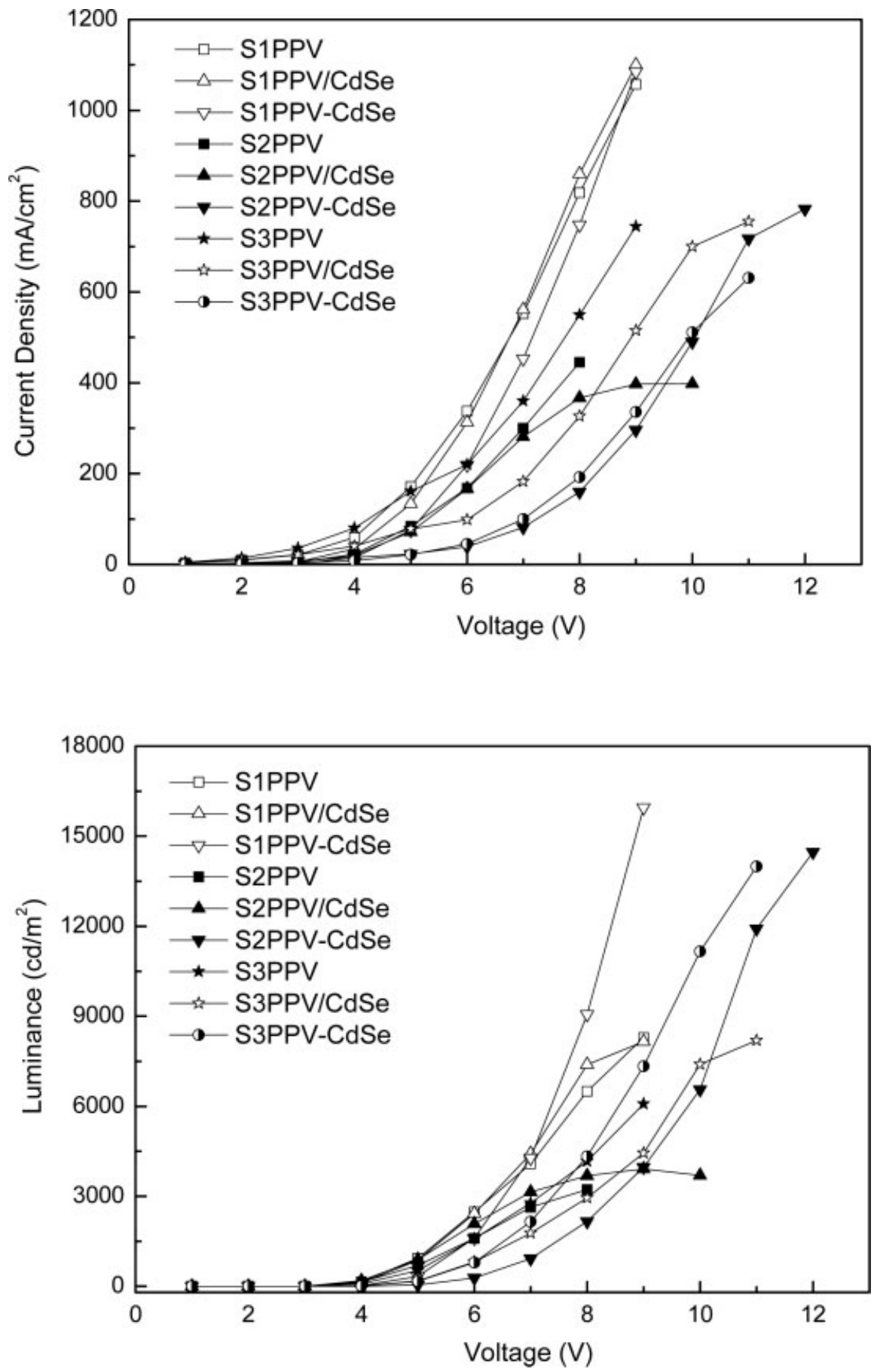

Figure 5. (a) Current density-voltage and (b) luminescence-voltage characteristics of these materials in ITO/PEDOT/polymer/Ca/Al devices.

and carrier mobility measurement. Figure 5 shows the energy level diagram of S1PPV-CdSe-S3PPVCdSe and CdSe/ZnS. To consider direct charge injection, holes and electrons may be trapped at $\mathrm{CdSe} / \mathrm{ZnS}$ owing to the relatively large energy barriers. This is also approved from the decreased cur- rent density under same driving voltage. As the $\mathrm{CdSe} / \mathrm{ZnS}$ content increased, the current density decreased. The holes and electrons can be trapped by CdSe and the charge flow throughout the device is thus restricted. The trapping charges stay at CdSe inside light-emitting layer to recombine to 
(a)

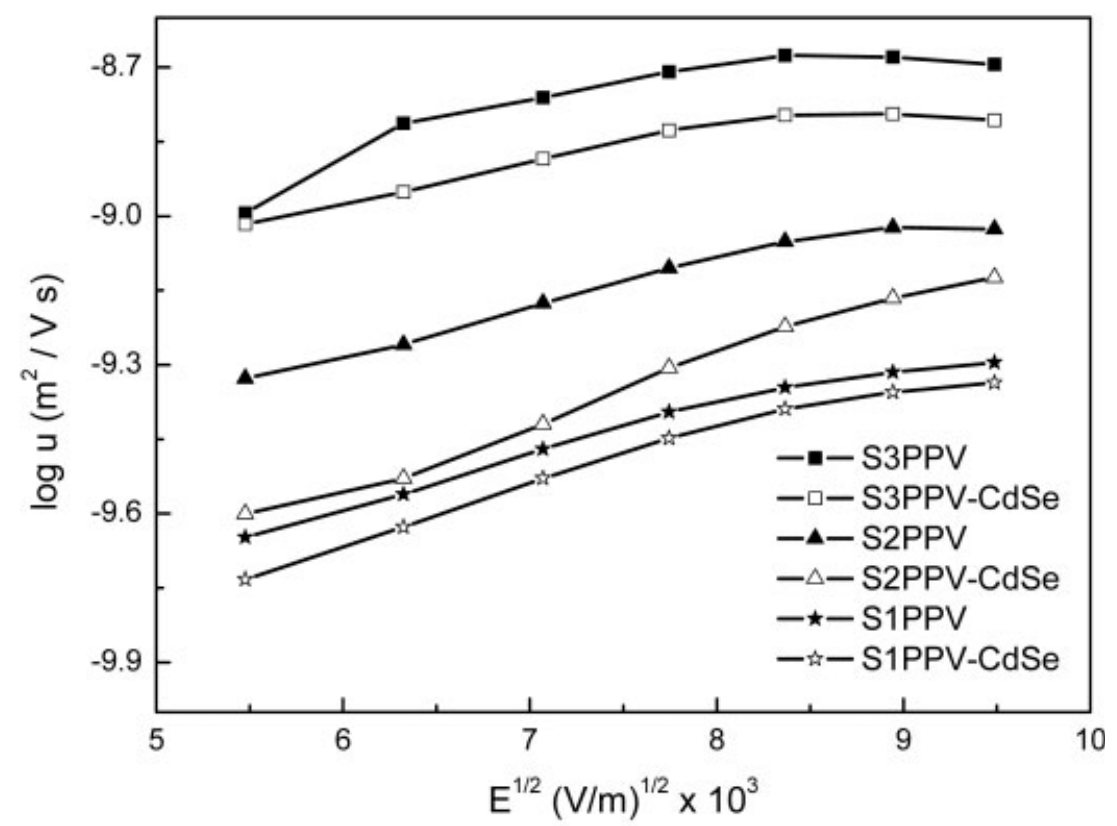

(b)

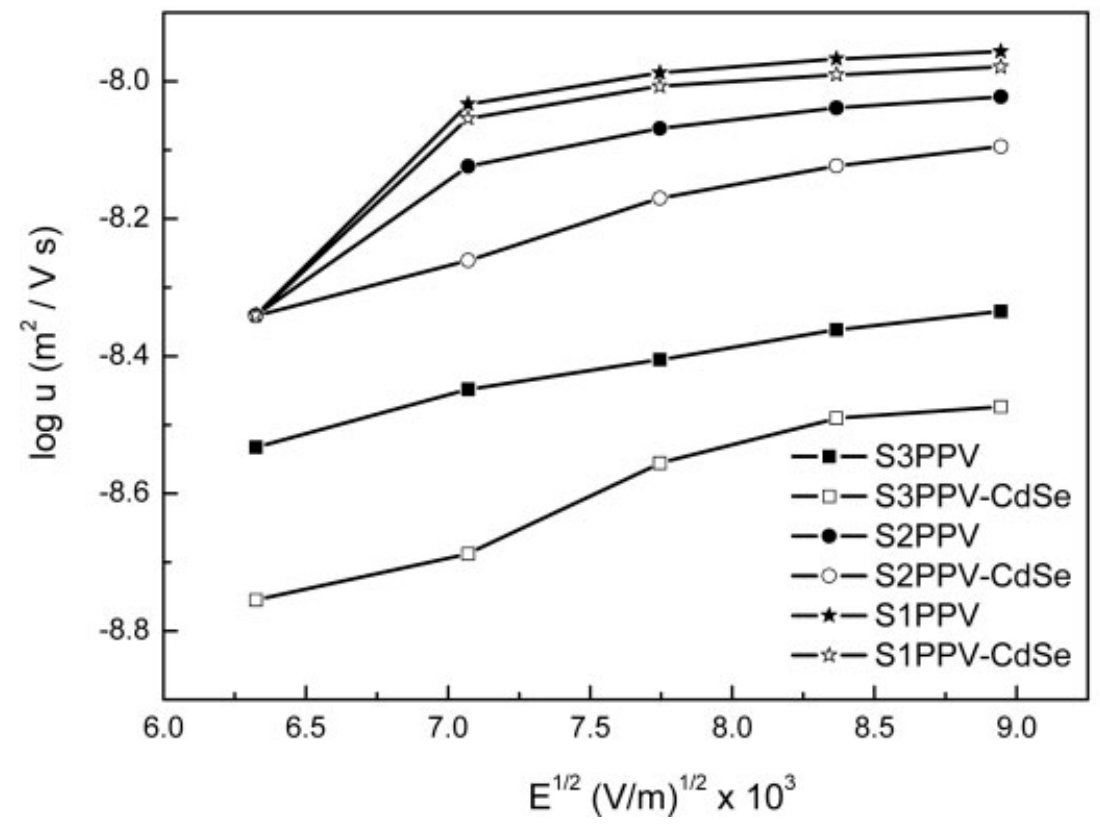

Figure 6. Current density-voltage characteristics of (a) hole-only and (b) electrononly devices.

form excitons. The probability of exciton formation in light-emitting layer increased and thus enhanced the device performance. The hole and electron injection/transporting properties of these materials were further investigated with using "hole-only" and "electron-only" devices. ${ }^{20,21}$ The structure of a typical "hole-only" device is ITO/PEDOT/polymer/Au. In this device hole injection is pre- 
dominant; holes can thus be injected into polymer layer and pass throughout the device to measure its mobility. On the other hand, the structure of a typical "electron-only" device is ITO/Al/polymer/Ca/Al. In this case electron injection is relatively major; electrons are injected into polymer layer and pass throughout the device to measure its mobility. The space charge limited current (SCLC) of single carrier is given by

$$
J=9 \varepsilon \varepsilon_{0} \mu V^{2} / 8 d^{3}
$$

where $\varepsilon \varepsilon_{0}$ is the permittivity of polymer, $\mu$ is the carrier mobility, and $d$ is the film thickness. Figure 6(a) shows hole mobility $(\log \mu)$ versus electric field $\left(E^{1 / 2}\right)$ curve obtained from "holeonly" devices, and Figure 6(b) shows electron mobility $(\log \mu)$ versus electric field $\left(E^{1 / 2}\right)$ curve obtained from "electron-only" devices. In Figure 6(a) it is seen that the hole mobility increased with increasing the content of sulfide group, referring a higher hole mobility. However, the hole mobility decreased with grafting polymers onto $\mathrm{CdSe} / \mathrm{ZnS}$. It means that $\mathrm{CdSe} /$ ZnS decrease the hole mobility. The decreased hole mobility affects the current density of device and enhances the quantum yield of device. In Figure 6(b), the electron current density decreased with increasing the content of sulfide group, referring a lower electron mobility. With grafting polymers onto $\mathrm{CdSe} / \mathrm{ZnS}$, the electron current density also decreased. It means that CdSe/ZnS decrease the electron mobility. For most PPV derivatives except CN-PPV, as reported in the literature, are found to be hole transport dominating. To our experiments the decreased hole mobility and decreased electron mobility were obtained; a charge balanced condition was achieved and helped to enhances the luminous yield of devices.

\section{CONCLUSIONS}

In summary, novel sulfide-substituted poly(1,4phenylene vinylene) derivatives (S1PPV-S3PPV) were successfully synthesized via the Gilch route. The CdSe/ZnS were grafted to the sulfur atoms by the ligand exchange reaction. A new peak at $1151 \mathrm{~cm}^{-1}$ formed in FT-IR after ligand exchange. This is attributed to the force formation between sulfur and CdSe. The GPC data showed higher molecular weights after grafting
CdSe/ZnS onto polymers. The resulting light emitting polymers with high molecular weights exhibited high thermal stabilities and good solubility in conventional organic solvents. The obtained polymers emitted bright green and yellow light with the maximum emission band located between 546 and $556 \mathrm{~nm}$ in film state. The HOMO and LUMO of the polymers are not significantly affected by incorporating CdSe/ZnS. The turn-on voltage of the double-layer devices using obtained light emitting polymers were in the range of $4-5 \mathrm{~V}$. As CdSe/ZnS was incorporated onto polymers via chemical bonding, the device performance was significantly increased as compared with their parent polymers. A maximum brightness of $15,960 \mathrm{~cd} / \mathrm{m}^{2}$ was observed for the device fabricated with S1PPV-CdSe as the emissive layer. A maximum luminous yield of $2.25 \mathrm{~cd} / \mathrm{A}$ was obtained for the device using S3PPV-CdSe as the emissive layer. The enhanced device performance was comprehended from charge trapping effect of CdSe/ZnS. Holes and electrons were trapped at $\mathrm{CdSe} / \mathrm{ZnS}$ inside light-emitting layer owing to the relative energy barriers to recombine to form excitons. The probability of the exciton formation increased in light-emitting layer and thus enhanced the device performance.

We thank the National Science Council (NSC) of the Republic of China (NSC 94-2120M-009-009) for financially supporting this research.

\section{REFERENCES AND NOTES}

1. Brus, L. E. Appl Phys A 1991, 53, 465.

2. Dabbousi, B. O.; Rodriguez-Viejo, J.; Mikulec, F. V. J Phys Chem B 1997, 101, 9463.

3. Colvin, V. L.; Schlamp, M. C.; Alivisatos, A. P. Nature 1994, 370, 354.

4. Dabbousi, B. O.; Bawendi, M. G.; Onitsuka, O.; Rubner, M. F. Appl Phys Lett 1995, 66, 1316.

5. Yang, Y.; Huang, J.; Liu, S.; Shen, J. C. J Mater Chem 1997, 7, 131.

6. Schlamp, M. C.; Peng, X.; Alivisatos, A. P. J Appl Phys 1997, 82, 5837.

7. Hikmet, R. A. M.; Talapin, D. V.; Weller, H. J Appl Phys 2003, 93, 3509.

8. Chandhary, S.; Ozkan, M.; Chan, W. C. W. Appl Phys Lett 2004, 84, 2925.

9. Fogg, D. E.; Radzilowski, L. H.; Dabbousi, B. O.; Schrock, R. R.; Thomas, E. L.; Bawendi, M. G. Macromolecules 1997, 30, 8433.

10. Skaff, H.; Emrick, T. Chem Commun 2003, 52. 
11. Skaff, H.; Ilker, M. F.; Coughlin, E. B.; Emrick, T. J Am Chem Soc 2001, 124, 5729.

12. Chen, K. B.; Li, H. C.; Chen, C. K.; Yang, S. H.; Hsieh, B. R.; Hsu, C. S. Macromolecules 2005, 38, 8617.

13. Friggeri, A.; Schönherr, H.; Manen, H. J.; Huisman, B. H.; Vancso, J.; Huskens, J.; Veggel, F. C. J. M.; Reinhoudt, D. N. Langmuir 2000, 16, 7757.

14. Locklin, J.; Patton, D.; Deng, S.; Baba, A.; Millan, M.; Advincula, R. C. Chem Mater 2004, 16, 5187.

15. Delmotte, A.; Biesemans, M.; Rahier, H.; Gielen, M. Synth Met 1993, 58, 325.
16. Shi, Y.; Liu, Y.; Yang, Y. J Appl Phys 2000, 87, 4254.

17. Chu, Q.; Pang, Y.; Ding, L.; Karasz, F. E. Macromolecules 2003, 36, 3848.

18. Hill, I. G.; Kahn, A. J Appl Phys 1999, 86, 4515.

19. Coe, S.; Woo, W. K.; Bawendi, M.; Bulovic, V. Nature 2002, 420, 800.

20. Manabe, K.; Hu, W.; Matsumura, M.; Naito, H. J Appl Phys 2003, 94, 2024.

21. Chirbase, D.; Chiguvare, Z.; Knipper, M.; Parisi, J.; Dyakonov, V.; Hummelen, J. C. J Appl Phys 2003, 93, 3376 . 